\title{
Acute Intravenous Injection Toxicity Study of Escherichia coli-Derived Recombinant Human Bone Morphogenetic Protein-2 in Rat
}

\author{
Jae Hyup Lee ${ }^{1,2}$, Eui-Nam Lee ${ }^{3}$, Bong-Soon Chang ${ }^{4}$, Choon-Ki Lee ${ }^{4}$ \\ ${ }^{I}$ Department of Orthopedic Surgery, SMG-SNU Boramae Medical Center, Seoul National University College of Medicine, Seoul, Korea \\ ${ }^{2}$ Institute of Medical and Biological Engineering, Medical Research Center, Seoul National University, Seoul, Korea \\ ${ }^{3}$ The Research and Development Institute, Daewoong Pharmaceutical Corporation, Yongin, Korea \\ ${ }^{4}$ Department of Orthopedic Surgery, Seoul National University Hospital, Seoul National University College of Medicine, Seoul, Korea
}

\section{Study Design: Prospective in vivo toxicity study.}

Purpose: To evaluate the conducted acute toxicity study of Escherichia coli (E. coli)-derived recombinant human bone morphogenetic protein-2 (rhBMP-2) with 6-weeks old Sprague-Dawley rats.

Overview of Literature: rhBMP-2 has well-known osteoinductivity and it is used as a bone graft substitute. E. coli-derived rhBMP-2 can be mass-produced with relatively low costs. E. coli-derived rhBMP-2 facilitates osteoblastic differentiation and bone formation in vitro and in vivo. However, studies regarding side effects or toxicity of $E$. coli-derived rhBMP-2 have not been published. Thus, we conducted the acute toxicity study of $E$. coli-derived rhBMP-2 on 6-weeks old Sprague-Dawley rats.

Methods: One mg of BMP-2 was diluted in $0.285 \mathrm{~mL}$ of glycine buffer to prepare high BMP-2 concentrations $(3.5 \mathrm{mg} / \mathrm{mL})$. Intermediate $(0.9 \mathrm{mg} / \mathrm{mL})$ or low $(0.35 \mathrm{mg} / \mathrm{mL})$ concentrations of BMP-2 solution was prepared by serial dilutions. The compound was administrated at a dose of $0,0.7,1.8,7 \mathrm{mg} / \mathrm{kg}$ by single intravenous injection to five of male and female rats. After the injection, the gross general observations including changes of body weight and histopathological analysis was performed for 14 days.

Results: No animal was found dead during the experiment and the body weight changes were both statistically insignificant in the control and experimental groups. No abnormal sign was shown in general observations and autopsy examinations.

Conclusions: Thus, the lethal dose of E. coli-derived rhBMP-2 should be higher than $7 \mathrm{mg} / \mathrm{kg}$ with a single intravenous injection.

Keywords: Recombinant human-bone morphogenetic protein-2; Acute toxicity test; Mortality; Intravenous injection

\section{Introduction}

Recombinant human bone morphogenetic protein-2 (rhBMP-2) is a well-known osteoinductive bone graft substitute. With proper carriers, the rhBMP-2 has been popularized in various clinical applications. To date, rhBMP-2 is used in degenerative spine, spinal fusion sur- gery for vertebral fracture, fusion surgeries for non-union of extremity fracture, dental surgery, and maximal-facial surgery [1,2]. Currently, commercially available rhBMP-2 is mammalian cell-derived. Mostly, Chinese hamster ovarian $(\mathrm{CHO})$ cells are used for the generation of rhBMP-2, but the yields of rhBMP-2 are very low, resulting in the high costs [3]. On the contrary, Escherichia coli (E.

Received Jan 19, 2013; Revised May 12, 2013; Accepted May 21, 2013

Corresponding author: Jae Hyup Lee

Department of Orthopedic Surgery, SMG-SNU Boramae Medical Center, Seoul National University College of Medicine, Institute of Medical and Biological Engineering, Medical Research Center, Seoul National University , 20 Boramae-ro 5-gil, Dongjak-gu, Seoul 156-707, Korea

Tel: +82-2-870-2314, Fax: +82-2-870-3863, E-mail: spinelee@snu.ac.kr 
coli)-derived rhBMP-2 is able to be mass produced with relatively low cost [4]. In cultured human mesenchymal stem cells, the E. coli-derived rhBMP-2 showed osteoblastic differentiation efficiency comparable to $\mathrm{CHO}$ cell derived BMP-2 [4]. Successful bone fusion by $E$. coli-derived rhBMP-2 was reported in experimented animals such as rats and rabbits $[4,5]$.

For further clinical application, the toxicity of $E$. coliderived rhBMP-2 should be considered but the study about its toxicity has not yet been done extensively. Systemic toxicity can be evaluated in several ways as follows: 1) single injection with excessive level of the clinical dose to determine the lethal dose, 2) repetitive injections of relatively high doses for several weeks (short period), 3) repetitive injections of relatively high doses for several months (long period). The E. coli-derived rhBMP-2 has never been evaluated on its toxicity with the above-mentioned methods.

Thus, in the present study, we examined the possible toxicity of $E$. coli-derived rhBMP-2 by single intravenous injection into Sprague-Dawley rats. Also, a lethal dose was suggested in this study.

\section{Materials and Methods}

\section{Materials}

E. coli-derived rhBMP-2 (A C1147H1779N321O328S19, $2.6 \mathrm{kDa}$ ) was obtained from Daewoong Pharmaceutical (Seoul, Korea). RhBMP-2 was prepared in glycine carrier buffer containing glutamic acid, glycine, sucrose, $\mathrm{NaCl}$, polysorbate 80 and $\mathrm{NaOH}$ in distilled water. High BMP-2 concentration, consisting $1 \mathrm{mg}$ of BMP-2 diluted in 0.285 $\mathrm{mL}$ of glycine buffer $(3.5 \mathrm{mg} / \mathrm{mL})$ was prepared and intermediate $(0.9 \mathrm{mg} / \mathrm{mL})$ or low $(0.35 \mathrm{mg} / \mathrm{mL})$ concentrations of BMP-2 solution was prepared by serial dilutions. All BMP-2/carrier solution was freshly prepared.

\section{Animals}

This study was conducted under a Biotoxtech (Cheongwon, Korea) institutional animal care and use committeeapproved protocol (\#09588) and in accordance with Good Laboratory Practice as outlined Korea Food and Drug Administration notification \#2009-102 and \#2009116. Research has been performed based on the Institutional Guide for the Care and Use of Laboratory Animals, and the ethical treatment of all experimental animals has been maintained.

Forty-eight 5-week-old Sprague-Dawley (Charles River Breeding Laboratories: $\mathrm{CD}[\mathrm{SD}]$ ) rats were obtained from Oriental Bio Inc. (Namyangju, Korea). Of 48 animals, 24 were male and 24 were female. The range of body weight was from 124.3 to $140.2 \mathrm{~g}$ for males and from 105.0 to $118.4 \mathrm{~g}$ for females. All animals were carefully examined and weighed (CP3202S, Sartorius, Goettingen, Germany) when obtained from the supplier.

During the 7 days of acclimation period, general symptoms were monitored once a day. When admitted to the animal room, the animals were checked for general symptoms in quarantine station for 3 days before they are transferred. On the last day of acclimation period, good health status of all animals was confirmed by measuring weights and monitoring general symptoms and weight changes. During the acclimation period, all the animals were marked on their tails with red-colored permanent pen to distinguish each other and animal cages were labeled with identification cards. During the experiments, each group of animals was indicated with blue-colored permanent pen on their tails and the cages were labeled with colored-identification cards.

After 7 days of the adjustment period, 4 of males and females, which exhibited extreme body weights, were excluded in this study. The remaining 40 animals were divided into 4 groups with the average body weight being nearly the same amongst the groups.

The rats were housed in stainless steel cages in a room maintained at $21.0^{\circ} \mathrm{C}$ to $22.9^{\circ} \mathrm{C}$ with relative humidity of $43.5 \%$ to $57.9 \%$ and airflow controls (10-15 air changes per hour). The animals were maintained in a 12:12 dark to light cycle (lights on from 7:00 to 21:00, 150-300 Lux). Rats were fed with lab diets (Teklad Certified Irradiated Global 18\% Protein Rodent Diet 2918C, Harlan Laboratories Inc., Madison, WI, USA) and filtered tap water. The cages were changed, cleaned, and autoclaved every 2 weeks.

\section{Test substance administration}

For clinical application, rhBMP-2 is implanted into where bone defects occur. However, in this study, a single dose of intravenous toxicity study was carried out in rats. The animals were injected intravenously through the lateral tail veins at an injection rate of $2 \mathrm{~mL} / \mathrm{min}$. In spinal fu- 
Table 1. Composition of control and experimental groups and dose for a single injection

\begin{tabular}{lcccc}
\multicolumn{1}{c}{ Group } & $\begin{array}{c}\text { Dose intravenous } \\
(\mathrm{mg} / \mathrm{kg})\end{array}$ & $\begin{array}{c}\text { Amount } \\
(\mathrm{mL} / \mathrm{kg})\end{array}$ & \multicolumn{2}{c}{ No. of rats } \\
\cline { 3 - 5 } G1 (control group) & 0 & 2 & 5 & 5 \\
\hline G2 (low dose group) & 0.7 & 2 & 5 & 5 \\
G3 (intermediate dose group) & 1.8 & 2 & 5 & 5 \\
G4 (high dose group) & 7 & 2 & 5 & 5 \\
\hline
\end{tabular}

Table 2. Mortality and approximate lethal dose of single intravenous toxicity study in Sprague-Dawley rats (group summary)

\begin{tabular}{|c|c|c|c|c|c|c|c|c|c|c|c|c|c|c|c|c|c|c|c|}
\hline \multirow{2}{*}{ Sex } & \multirow{2}{*}{$\begin{array}{l}\text { Group/dose } \\
\text { (mg/kg) }\end{array}$} & \multirow{2}{*}{$\begin{array}{c}\text { No. of } \\
\text { animals }\end{array}$} & \multicolumn{15}{|c|}{ Day after treatment } & \multirow{2}{*}{$\begin{array}{c}\text { Mortality }(\%) \\
\text { (dead/total) }\end{array}$} & \multirow{2}{*}{$\begin{array}{c}\text { Approximate } \\
\text { lethal dose } \\
(\mathrm{mg} / \mathrm{kg})\end{array}$} \\
\hline & & & 0 & 1 & 2 & 3 & 4 & 5 & 6 & 7 & 8 & 9 & 10 & 11 & 12 & 13 & 14 & & \\
\hline \multirow[t]{4}{*}{ Male } & G1 (0) & 5 & 0 & 0 & 0 & 0 & 0 & 0 & 0 & 0 & 0 & 0 & 0 & 0 & 0 & 0 & 0 & $0(0 / 5)$ & $>7$ \\
\hline & G2 (0.7) & 5 & 0 & 0 & 0 & 0 & 0 & 0 & 0 & 0 & 0 & 0 & 0 & 0 & 0 & 0 & 0 & $0(0 / 5)$ & \\
\hline & G3 (1.8) & 5 & 0 & 0 & 0 & 0 & 0 & 0 & 0 & 0 & 0 & 0 & 0 & 0 & 0 & 0 & 0 & $0(0 / 5)$ & \\
\hline & G4 (7) & 5 & 0 & 0 & 0 & 0 & 0 & 0 & 0 & 0 & 0 & 0 & 0 & 0 & 0 & 0 & 0 & $0(0 / 5)$ & \\
\hline \multirow[t]{4}{*}{ Female } & $\mathrm{G} 1(0)$ & 5 & 0 & 0 & 0 & 0 & 0 & 0 & 0 & 0 & 0 & 0 & 0 & 0 & 0 & 0 & 0 & $0(0 / 5)$ & $>7$ \\
\hline & $\mathrm{G} 2(0.7)$ & 5 & 0 & 0 & 0 & 0 & 0 & 0 & 0 & 0 & 0 & 0 & 0 & 0 & 0 & 0 & 0 & $0(0 / 5)$ & \\
\hline & G3 (1.8) & 5 & 0 & 0 & 0 & 0 & 0 & 0 & 0 & 0 & 0 & 0 & 0 & 0 & 0 & 0 & 0 & $0(0 / 5)$ & \\
\hline & G4 (7) & 5 & 0 & 0 & 0 & 0 & 0 & 0 & 0 & 0 & 0 & 0 & 0 & 0 & 0 & 0 & 0 & $0(0 / 5)$ & \\
\hline
\end{tabular}

sion surgery, 1 to $8 \mathrm{mg}$ of rhBMP-2 is applied per patient (0.017-0.13 $\mathrm{mg} / \mathrm{kg}$ for $60 \mathrm{~kg}$ adult patient). In this study, to evaluate the lethal dose and toxicity of rhBMP-2, rats in the high dose group were injected with total doses of $7 \mathrm{mg} / \mathrm{kg}$, which was 50 to 410 times more of clinical doses. The intermediate dose group and low dose group were injected with $1.8 \mathrm{mg} / \mathrm{kg}$ and $0.7 \mathrm{mg} / \mathrm{kg}$ of rhBMP-2, respectively. In control group, $2 \mathrm{~mL}$ of carrier buffer was injected (Table 1).

\section{Methods}

At the day of injection (day 0), the animals were examined frequently $(1,2,4$, and 6 hours). From day 1 to day 14 , the rats were observed daily to note for toxic features including the kinds of toxic symptoms, the periods of symptom appearance and the periods of symptom recovery.

The body weight of all animals were measured before and after the injection (day $0,1,3,7$ ), and prior to sacrificing (day 14). All animals were sacrificed at day 14 by exsanguinations via the abdominal aorta after the carbon dioxide anesthesia and autopsy was followed. Histological examination was performed when gross abnormalities were observed.

\section{Statistical analysis}

The statistical analysis of body weight employed the SAS (ver. 9.1.3, SAS Institute Inc., Cary, NC, USA). To test homogeneity of variance, Bartlett's test was used (95\% of confidence interval). One-way analysis of variance was used to test significance. For all tests, $p$-values $<0.05$ were considered significant.

\section{Results}

\section{Mortality}

No animal was found dead during the test. Thus, the minimum single lethal dose was more than $7 \mathrm{mg} / \mathrm{kg}$ by the intravenous route (Table 2).

\section{Clinical observation}

None of male and female rats in 0, 0.7, 1.8, $7 \mathrm{mg} / \mathrm{kg}$ of rhBMP-2 
Table 3. Body weight of Sprague-Dawley rats in single intravenous toxicity study (group summary)

\begin{tabular}{|c|c|c|c|c|c|c|c|}
\hline \multirow{2}{*}{ Sex } & \multirow{2}{*}{$\begin{array}{l}\text { Group/dose } \\
\text { (mg/kg) }\end{array}$} & \multicolumn{5}{|c|}{ Day after treatment $(\mathrm{g})$} & \multirow{2}{*}{$\begin{array}{l}\text { Gain } \\
0-14\end{array}$} \\
\hline & & 0 & 1 & 3 & 7 & 14 & \\
\hline \multirow[t]{4}{*}{ Male } & $\mathrm{G} 1(0)$ & $202.2 \pm 7.4$ & $208.5 \pm 8.1$ & $227.0 \pm 9.6$ & $265.4 \pm 16.5$ & $330.2 \pm 24.6$ & $127.9 \pm 18.0$ \\
\hline & $\mathrm{G} 2(0.7)$ & $201.0 \pm 5.2$ & $207.6 \pm 6.0$ & $227.3 \pm 6.3$ & $268.1 \pm 9.4$ & $336.7 \pm 11.4$ & $135.7 \pm 10.0$ \\
\hline & $\mathrm{G} 3(1.8)$ & $199.1 \pm 6.0$ & $208.1 \pm 5.3$ & $226.4 \pm 5.6$ & $264.6 \pm 4.2$ & $328.8 \pm 7.4$ & $129.7 \pm 8.7$ \\
\hline & $\mathrm{G} 4(7)$ & $202.2 \pm 8.2$ & $209.5 \pm 9.6$ & $229.0 \pm 13.2$ & $265.7 \pm 19.0$ & $338.5 \pm 30.2$ & $136.3 \pm 22.1$ \\
\hline \multirow[t]{4}{*}{ Female } & $\mathrm{G} 1(0)$ & $151.8 \pm 5.9$ & $153.4 \pm 6.3$ & $163.4 \pm 4.2$ & $180.2 \pm 7.0$ & $207.7 \pm 9.2$ & $55.9 \pm 9.5$ \\
\hline & $\mathrm{G} 2(0.7)$ & $150.4 \pm 7.2$ & $153.7 \pm 7.9$ & $161.7 \pm 9.2$ & $177.5 \pm 8.5$ & $201.9 \pm 8.7$ & $51.5 \pm 7.2$ \\
\hline & G3 (1.8) & $151.9 \pm 4.9$ & $154.2 \pm 4.0$ & $162.9 \pm 5.4$ & $178.1 \pm 7.2$ & $201 \pm 7.9$ & $50.0 \pm 6.4$ \\
\hline & G4 (7) & $150.1 \pm 3.6$ & $155.7 \pm 3.9$ & $162.0 \pm 5.7$ & $176.0 \pm 6.5$ & $200.8 \pm 10.5$ & $50.7 \pm 11.1$ \\
\hline
\end{tabular}

Five animals per group were tested. Values are presented as mean \pm standard deviation.

Table 4. Necropsy findings of Sprague-Dawley rats in single intravenous toxicity study

\begin{tabular}{|c|c|c|c|c|c|c|c|c|}
\hline \multirow{2}{*}{ Sex/group } & \multicolumn{4}{|c|}{ Male } & \multicolumn{4}{|c|}{ Female } \\
\hline & G1 & G2 & G3 & G4 & G1 & G2 & G3 & G4 \\
\hline Dose (mg/kg) & 0 & 0.7 & 1.8 & 7.0 & 0 & 0.7 & 1.8 & 7.0 \\
\hline No. of animals & 5 & 5 & 5 & 5 & 5 & 5 & 5 & 5 \\
\hline No. remarkable findings & 5 & 5 & 5 & 5 & 5 & 5 & 5 & 5 \\
\hline No. of examined & 5 & 5 & 5 & 5 & 5 & 5 & 5 & 5 \\
\hline
\end{tabular}

groups showed abnormal clinical signs on the day of injection $(0.5,1,2,4,6$ hours). For 14 days following the injection, none of the animals showed abnormal clinical signs.

\section{Body weight changes}

In all experimental groups, no significant changes in body weights were noted before and after the injection. Body weights of all the rats including control group were increased after injections of the compound $(p<0.001)$. But the results were statistically insignificant (Table 3 ).

\section{General autopsy}

According to the gross observation, there was no definite abnormality in all groups (Table 4). Autopsies did not find any abnormalities in all the test and control groups. So, no additional histological studies were followed.

\section{Discussion}

Many studies and clinical trials have demonstrated that
BMP-2 enhances bone fusions, thus, the clinical application of BMP-2 has become common in spine surgery. However, its various side effects have been reported. BMP-2 affects the surrounding mesenchymal stem cells and pre-osteoblasts, resulting in serious side effects such as excessive and/or bone formations, osteolysis, or infections [6]. It also induced inflammatory reactions including seroma formation, radiculopathy and cord compressions [7]. Moreover, BMP-2 involved serious adverse effects such as dysphagia, soft tissue swelling, and pharyngeal edema accompanied by respiratory distresses after the application on anterior cervical surgeries $[8,9]$. Recently, genitourinary complications such as retrograde ejaculations in anterior lumbar surgery were reported $[10,11]$. Mostly, these complications were locally induced at where rhBMP-2 was implanted for the bone fusions, and systemic side effects were unlikely to be involved. Since rhBMP-2 is a soluble protein, which can be inserted to intramedullary cavity through the carrier. Also, it can flow into the systemic circulation via blood streams when it is implanted adjacent to cancellous bone of host or to the place with high blood flows such as vertebral body. However, lethal dose of rhBMP-2 is not known and the 
toxicity of E. coli-derived rhBMP-2 has never been reported. Thus, we injected high doses of E. coli-derived rhBMP-2 via intravenous to evaluate systemic toxicity. It is speculated that $\mathrm{CHO}$-cell derived rhBMP-2 induces various complications and this phenomenon is associated with the clinical dosages. Previously, high dose of $10 \mathrm{mg}$ was used in spinal fusions. Currently, 1 to $10 \mathrm{mg}$ of rhBMP-2 is being used.

In this study, no animal was found dead after the injection. As shown in animal studies, half-life of rhBMP-2 is 7 to 16 minutes in case of systemic implant or 8 days in local implant with collagen spongy [12]. Thus, it is plausible that rapid clearances play important roles in lowering systemic toxicity. Due to its high osteoinductivity, rhBMP-2 may induce ectopic bone formation in organs with high blood flow such as lung, kidney, brain, liver during systemic circulation and it can be found in gross autopsy [13]. But in this study, general observations and autopsy (lung ring sysparenchyma, kidney and brain) did not show any abnormal sign such as ectopic bone formation even under the conditions of high dose systemic injections. It is possibly because of short half-life of rhBMP-2 and its fast circulation which makes it hard to signal to adjacent cells. Since this study focused on the effects of rhBMP-2 for 2 weeks of treatment with single injection, it is hard to draw the conclusion about longterm side effects or the effects of repetitive injections. Despite the limitation, this study provides a significant view about how single intravenous injection of $E$. coli-derived rhBMP-2 affects mortality and gross abnormality.

\section{Conclusions}

Thus, the lethal dose of single injection should be higher than $7 \mathrm{mg} / \mathrm{kg}$ in SD rats. Overall, this study suggests that intravenous injection of $E$-coli-derived rhBMP-2 within the clinical dose is highly unlikely to affect mortality.

\section{Conflict of Interest}

No potential conflict of interest relevant to this article was reported.

\section{Acknowledgments}

This work was supported by a clinical research grant-inaid from the SMG-SNU Boramae Medical Center (No.
03-2011-4).

\section{References}

1. Axelrad TW, Einhorn TA. Bone morphogenetic proteins in orthopaedic surgery. Cytokine Growth Factor Rev 2009;20:481-8.

2. Westerhuis RJ, van Bezooijen RL, Kloen P. Use of bone morphogenetic proteins in traumatology. Injury 2005;36:1405-12.

3. Israel DI, Nove J, Kerns KM, Moutsatsos IK, Kaufman RJ. Expression and characterization of bone morphogenetic protein-2 in Chinese hamster ovary cells. Growth Factors 1992;7:139-50.

4. Lee JH, Jang SJ, Koo TY, et al. Expression, purification and osteogenic bioactivity of recombinant human BMP-2 derived by escherichia coli. Tissue Eng Regen Med 2011;8:8-15.

5. Lee JH, Yu CH, Yang JJ, et al. Comparative study of fusion rate induced by different dosages of Escherichia coli-derived recombinant human bone morphogenetic protein-2 using hydroxyapatite carrier. Spine J 2012;12:239-48.

6. Owens K, Glassman SD, Howard JM, Djurasovic M, Witten JL, Carreon LY. Perioperative complications with rhBMP-2 in transforaminal lumbar interbody fusion. Eur Spine J 2011;20:612-7.

7. Anderson DW, Burton DC, Jackson RS. Postoperative cervical myelopathy and cord compression associated with the use of recombinant bone morphogenetic protein-2 in posterior cervical decompression, instrumentation, and arthrodesis: a report of two cases. Spine (Phila Pa 1976) 2011;36:E682-6.

8. Benglis D, Wang MY, Levi AD. A comprehensive review of the safety profile of bone morphogenetic protein in spine surgery. Neurosurgery 2008;62:ONS42331.

9. Robin BN, Chaput CD, Zeitouni S, Rahm MD, Zerris VA, Sampson HW. Cytokine-mediated inflammatory reaction following posterior cervical decompression and fusion associated with recombinant human bone morphogenetic protein-2: a case study. Spine (Phila Pa 1976) 2010;35:E1350-4.

10. Carragee EJ, Hurwitz EL, Weiner BK. A critical review of recombinant human bone morphogenetic protein-2 trials in spinal surgery: emerging safety concerns and lessons learned. Spine J 2011;11:471- 
91.

11. Smoljanovic T, Rakovac M, Bojanic I. Could chronic host inflammatory response be responsible for delayed onset of retrograde ejaculation after the labeled use of recombinant human bone morphogenetic protein-2? Spine J 2011;11:167-8.

12. Poynton AR, Lane JM. Safety profile for the clinical use of bone morphogenetic proteins in the spine. Spine (Phila Pa 1976) 2002;27(16 Suppl 1):S40-8.

13. Lee JH, Lee EN, Nam SH. The short-term effects of repetitive E. coli-derived rhBMP-2 administration through intravenous injection in rats. Drug Chem Toxicol 2014;37:40-7. 